RESENHA

\title{
Olhar africano no tornar-se feminista: Por uma nova geração no mundo de Chimamanda
}

\author{
CHIMAMANDA NGOZI ADICHIE
}

\section{La mirada africana en convertirse en feminista: Por una nueva generación en el mundo de Chimamanda}

\section{CHIMAMANDA NGOZI ADICHIE}

RESUMO: A resenhada, Chimamanda Ngozi Adichie, autora do best-seller internacional Americanah, é feminista, negra, nigeriana nascida em Enugu, em 1977, com obras publicadas desde 2008. Vive entre a Nigéria e os Estados Unidos devido a uma bolsa de estudos recebida pela MacArthur Foundation. Nesse manifesto em forma de carta, contendo quinze sugestões para criar filhos na perspectiva feminista, a autora adentra o tema igualdade de gênero, e nessa incursão insere sua experiência no contexto do feminismo. Nesse sentido, vários fatores da imposição de gênero são elementos de sua reflexão, que parte da infância com os brinquedos sexuados às diferenças de papéis no casamento. No nosso entendimento sobre o texto intitulado "Para educar crianças feministas - um manifesto", trata-se de uma maneira de preparar a nova geração para a igualdade nas relações de gênero, e que tende a ultrapassar territórios, portanto, estende-se ao mundo.

Palavras-chave: Chimamanda Adichie; África; Gênero; Educação feminista

RESUMEN: La reseñada, Chimamanda Ngozi Adichie, autora del best-seller internacional Americanah, es feminista, negra, nigeriana nacida en Enugu, en 1977, con obras publicadas desde 2008. Vive entre Nígeria y Estados Unidos debido a una beca recibida por la beca MacArthur Foundation. En este manifiesto en forma de carta, conteniendo quince sugerencias para criar hijos en la perspectiva feminista, la autora adentra al tema igualdad de género, y en esa incursión inserta su experiencia en el contexto del feminismo. En ese sentido, varios factores de la imposición de género son elementos de su reflexión, que parte de la infancia con los juguetes sexuados, a las diferencias de papeles en el matrimonio. En nuestro entendimiento el texto titulado "Para educar los niños feministas - un manifesto" es una manera de preparar a la nueva generación para la igualdad en las relaciones de género, y que tiende a sobrepasar territorios, por lo tanto, se extiende al mundo.

Palabras clave: Chimamanda Adichie; África; Género; Educación feminista.

\footnotetext{
${ }^{1}$ Doutoranda em Difusão do Conhecimento DMMDC - Doutorado Multi-Institucional e Multidisciplinar/UFBA

2 Professor Adjunto da FACED/UFBA (Faculdade de Educação da Universidade Federal da Bahia) e do Doutorado Multi-Institucional e Multidisciplinar em Difusão do Conhecimento - DMMDC.
} 


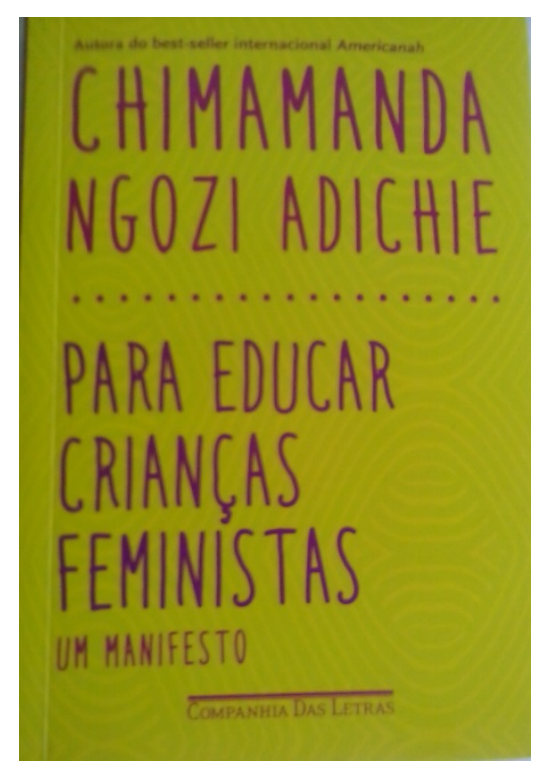

Tradução:

Denise Bottmann.

$1^{\mathrm{a}}$ ed. São Paulo: Companhia das Letras, 2017.

Obra original:

Dear Ijeawele, or A Feminist Manifesto in Fifteen Suggestions

ISBN: 978-85-359-2851-8

A obra "Para educar crianças feministas - um manifesto", da autora Chimamanda Ngozi Adichie, publicada em 2017, é desdobrada de uma carta escrita para uma amiga quando tem sua primeira reprodução, tornando-se mãe. Partindo da experiência como mãe e filha, Chimamanda lhe dá sugestões de como educar a sua criança, abordando várias questões que estão em debate no feminismo - e de forma específica no feminismo negro africano, cuja cultura sofreu fortemente influências da colonização.

Trata de uma estratégia para mudanças nas relações de gênero, pautando-se em igualdade e indo contra as imposições, as quais formam e reforça o binarismo, constituindo prejuízo às mulheres e em favor dos homens, constatado como privilégio deste último, por meio do discurso da biologia, criando, portanto, desigualdades entre os sexos em diversos contextos.

"Para educar crianças feministas - um manifesto" é uma maneira de preparar a nova geração para a igualdade nas relações de gênero: no serviço doméstico, nos comportamentos, nos brinquedos, na construção identitária, no casamento, sobretudo considerada pela autora como estratégia de dominação masculina, tendo sustentação na jurisprudência, em forma de leis, naturalizando-se.

Uma característica do casamento, que a autora aponta como imposição de gênero, é a mudança do nome da mulher para o nome do homem, para ela uma forma jurídica de institucionalizar a submissão feminina. E destaca três elementos como consequência: o desgaste com a energia mental em mudar a documentação, a carteira de motorista, o passaporte, os títulos acadêmicos, assinatura, contas bancárias, entre outras; a mudança 
psíquica e o novo tornar-se. (46/7). Além disso, é uma perda de identidade imposta, pois, casadas, as mulheres devem adequar-se a uma nova identidade. Dessa forma relaciona a questão como violência, ou diríamos, sutil violência de gênero.

Apesar de ser casada, Adichie não leva o nome do marido, contudo, não está longe da violência de imporem-lhe o nome do seu marido, como fez uma jornalista " [...] ao descobrir que eu era casada, e como eu pedi que parasse, pois meu nome não era aquele?”. (42-3). Ao tratar da questão como uma contestação à norma, ela fala da consequência disso, quando recebeu hostilidade dos nigerianos, sendo muito maior da parte das mulheres.

Para as/os que alegam que antes do casamento o sobrenome da mulher é proveniente do seu pai, logo, uma questão do patriarcado, Chimamanda encontra uma justificativa. Certa disso, porém, ela argumenta que o nosso sobrenome proveniente do pai é dado desde o nascimento, nossa identidade é construída nesse contexto; já a mudança que ocorre no casamento tem outra conotação. Portanto, deveria ser uma questão de escolha, desejo e não de pressão social dos padrões vigentes (44).

A respeito do privilégio dos homes (61-2), a autora o entende a partir da biologia, utilizada como razão para as normas sociais na cultura africana. E então se reporta ao nome da criança nascida, que é relacionada à biologia e à superioridade física, como formas de manter a superioridade masculina no contexto geral.

Segundo a autora (63), "para muitas mulheres igbos, o condicionamento é tão grande que as mulheres pensam que a progênie é apenas do pai. Conheço mulheres que abandonaram casamentos ruins, mas não foram 'autorizadas' a levar ou sequer a ver os filhos porque eles pertencem ao homem". Destarte, se a questão fosse mesmo biológica "[...] as crianças então seriam identificadas pelas mães e não pelos pais, pois, quando a criança nasce, o genitor biológico - e incontestável - é a mãe" (p. 62-3). Segundo pensa, a biologia não deve ser aceita para qualquer norma social. Além disso, não existe norma social que não possa ser alterada (64).

Historicizando a imposição de gênero (23-4), esta começa o quanto antes na vida e se apresenta nas cores e brinquedos. Exemplificando, a autora insere suas experiências e contanos que foi à uma loja infantil e comprou uma roupa azul para a filha. Mas não foi tão simples: "A moça do caixa me disse que era o presente ideal para um garotinho. Falei que era para uma menininha. Ela fez uma cara horrorizada: ‘Azul para uma menina?’”. 
Seguindo, ao observar a seção dos brinquedos, a autora diz que esta era organizada por gênero, do tipo ativo para os meninos (trens, carrinhos), e para as meninas eram do tipo passivo (a maioria bonecas). O mundo começa a inventar papéis de gênero desde cedo.

Sobre o serviço doméstico - e em particular a cozinha como inerente às mulheres -, em se tratando do casamento (heterossexual), quando os homens o fazem, estão sendo gentis para com a companheira. A autora aponta que não tem nada que ver com o biológico/ natureza, mas sendo um processo de construção. Para ela, os homens que não sabem cozinhar devem aprender. "Saber cozinhar não é algo que vem pré-instalado na vagina. Cozinhar se aprende. Cozinhar - o serviço doméstico em geral - é uma habilidade que se adquire na vida, e que teoricamente homens e mulheres deveriam ter" (21).

$\mathrm{Na}$ questão do comportamento a autora entende que contribui na violência, no assédio sexual, quando diz ser comum que "ensinamos as meninas a serem agradáveis, boazinhas, fingidas. E não ensinamos a mesma coisa aos meninos. É perigoso. Muitos predadores sexuais se aproveitam disso. Muitas meninas ficam quietas quando são abusadas, porque querem ser boazinhas." (48).

Chimamanda Adichie é adepta do esporte, com passagem pelo futebol na infânciaadolescência, sendo o esporte uma porta para o empoderamento de muitas mulheres que resistem às normas, aos padrões de gênero e tornam-se, às vezes, declaradas feministas. (54). Mas reconhece que as meninas geralmente param de praticar esportes ao chegar à puberdade. O desenvolvimento dos seios e a percepção de si mesma influenciam na decisão delas “_ Eu parei de jogar futebol quando meus seios começaram a crescer, pois tudo o que eu queria era esconder a existência deles, e correr e colidir não ajudava”. (55).

$\mathrm{O}$ esporte na demanda do feminismo é visto quando a autora sugere que as meninas desde cedo devem ser incentivadas à prática esportiva, a fazer caminhadas juntas, nadar, correr, jogar tênis, futebol, pingue-pongue. "Todos os tipos de esportes. Qualquer tipo de esporte. Penso que é importante não só por causa dos evidentes benefícios para a saúde, mas porque pode ajudar com todas as inseguranças quanto à imagem do corpo que o mundo lança sobre as meninas". (54).

Com suas sugestões feministas, Adichie não se coloca contra a feminilidade, deixando claro que feminismo e feminilidade não são mutuamente excludentes. Como pensa, ser feminista não deve ter a opção de mudança de identidade de gênero, como às vezes parece. "Não pense que criá-la como feminista significa obrigá-la a rejeitar a feminilidade [...] É misógino sugerir o contrário". (55). 
Ao discutir sobre misoginia, e como prova de que misoginia não atinge somente os homens, a autora também aponta a misoginia entre as mulheres, expondo que a bondade feminina é tão normal quanto a maldade feminina. Assim, afirma que existem muitas mulheres no mundo que não gostam de outras mulheres. "A misoginia feminina existe e esquivar-se a reconhecê-la é criar oportunidades desnecessárias para que as antifeministas tentem desacreditar o feminismo". (75). É nítido que a autora encontra misoginia entre as mulheres, exclusivamente entre as antifeministas.

Em outra conotação diante do sexismo, ela mostra que as ações de combater sexismo e racismo incomodam sexistas e racistas, advertindo-nos que, com o feminismo no ato de confrontar as normas, essas mulheres (feministas) não são vistas, muitas vezes, como pessoas normais: em parte, são todas marcadas como não mulheres, em parte, são raivosas. Nesse sentido, Chimamanda lembra um caso ocorrido com ela, quando foi acusada de ser raivosa em um artigo escrito por um sujeito do sexo masculino. (31-2).

Em resposta ela expressa: "Claro que tenho raiva. Tenho raiva do racismo. Tenho raiva do sexismo. Mas eu recentemente percebi que tenho mais raiva do sexismo do que do racismo”. (31). E explica: “... porque a injustiça racial é facilmente reconhecida, o sexismo não". Nosso olhar sobre a descrição implica que a injustiça racial não é reconhecida em todo o território mundial. Cremos que depende, de fato, do lugar de fala, pois não podemos dizer o mesmo no contexto brasileiro.

Assim, compreendemos que essa marca de raiva é atribuída às mulheres negras (AUDRE LORDE, 1981), pelo fato de que essa categoria não denuncia tão somente o sexismo, mas inclui o racismo e seus efeitos. Igualmente notamos que combater o racismo no interior do feminismo, denunciar o privilégio das mulheres brancas na questão de gênero é ser raivosa e agressiva (LÉLIA GONZALES, 1979; bell hooks, 2015). Dessa maneira, incomodam não tão somente os homens brancos, mas em parte o feminismo branco também.

Contrário ao que muito se conhece sobre o lugar destinado às mulheres negras (de cor), Chimamanda revela outro lugar, que é o seu lugar de fala: a mulher negra, de classe social média, portadora de títulos acadêmicos, autônoma e que trabalha fora em atividades desejáveis.

Nessa acepção, o texto tem um enfoque que destitui o lugar reservado às mulheres negras: o da classe menos favorecida, da pobre, do serviço braçal e da cozinha da/o branca/o. Em um termo "submissão das mulheres negras" (ou de cor, como conceitua o feminismo norte-americano) em relação à equivocadamente legítima mulher - branca, como passaram a 
ser as categorias de mulheres após a colonização, fortalecida na experiência da escravidão (ANGELA DAVIS, 2016). Ao escavar a história em suas diversas formas (escrita, grafada, pelo signo ou oral), notamos que não foi assim desde sempre, revisitando os estudos sobre a colonização (ACHILLE MBEMBE, 2013).

Apesar de a autora universalizar a categoria mulher, parece ser a sua intenção apontar o outro lugar da mulher negra: de classe média, autônoma e com igualdade de fato, entre os sexos e as raças. Chimamanda parece chamar a atenção, revelando nessa carta uma mulher africana, de certa forma socialmente em pé de igualdade com as outras etnias. Contudo, a autora transpassa e ignora esse cansativo e debatido diálogo ainda persistente no discurso, sobre o mito da mulher africana como a selvagem, a mulher que vive no mato com as onças.

Dessa forma, a autora não se remete ao contexto estereotipado marcado nas mulheres negras, nem às funções desqualificadoras, de baixo nível social a estas relegadas, sendo, portanto, uma forma renovada da literatura feminista negra.

O texto traz outra perspectiva para a escrita negra, já que a autora não trata de resiliência, de como mudar de história de vida, nem de subalternidade racial, mas de igualdade no interior do sexo e sugestões para a igualdade entre os sexos. Em suma, chamounos a atenção a mulher negra não tão somente empoderada, mas em pé de igualdade com a mulher branca. Esse é outro lugar que vem sendo alcançado por essa categoria ainda submissa, de fato, considerando as exacerbadas desigualdades entre as raças, no contexto dos territórios e em seu interior.

\section{Referências}

DAVIS, Angela. Mulheres, raça e classe. Tradução Regina Heci Candiani. 1. ed. São Paulo: Boitempo, 2016.

GONZALEZ, Lélia. Cultura, etnicidade, trabalho: efeitos linguísticos e politicos da exploração da mulher. Comunicação apresentado no VIII encontro Nacional da Latin American Studies Association. Pittesburgh, Pensilvânia, abr. 1979 (mimeo).

HOOKS, bell. Mulheres negras: moldando a teoria feminista. Black women: shaping feminist theory. Revista Brasileira de Ciências Política. Brasília, 16, p.193-210, jan-abril, 2015.

LORDE, Audre. Os usos da raiva: mulheres respondendo ao racismo, 1981. Consultado em:>https://we.riseup.net/radfem/usos-da-raiva-mulheres-respondendo-ao-racismo-audr>.

MBEMBE, Achille. África Insubmissa: cristianismo, poder e estado na sociedade póscolonial: Paris: Edições Pedagogo, 2013. 
Recebido em: 20 de agosto de 2017.

Aceito em: 12 de outubro de 2017. 